\title{
O PLANO DE IMANÊNCIA DA ÁREA DE INFORMAÇÃO E A MÁQUINA DE GUERRA
}

\author{
Igor Soares Amorim* \\ Solange Puntel Mostafa
}

RESUMO Trata da noção de sociedade de controle na concepção de Deleuze e Guattari a fim de desenvolver uma abordagem crítica sobre a noção de informação para a Área de Informação. A noção de informação se vincula à sociedade de controle. A Área de Informação é comprometida com a gestão de fluxos comunicacionais. A informação é revelada como potencializadora da sociedade de controle na medida em que possibilita o controle dos dados. Ao controle, a informação é necessária em dois sentidos: na descentralização da ordem objetivando a subserviência e na extração dos dados que alimentam bancos computacionais. Assim, a aproximação entre essa área ao pensamento de Deleuze e Guattari se dá num movimento de resistência nos próprios fluxos informacionais. A informação se constitui entre enunciado e fala, e condiciona a transmissão da palavra de ordem. Mas a transmissão é envolta num agenciamento que precede as individualidades. Assim, mobilizar uma máquina de guerra para saltar de uma informação ao agenciamento coletivo pode ser um trajeto alternativo à Área de Informação.

Palavras-chave: Área de Informação. Sociedade de Controle. Máquina de Guerra. Informação. Informe.

\footnotetext{
* Mestre em Ciência da Informação pela Universidade Federal de Santa Catarina, Brasil. Doutorando em Ciência da Informação no Programa de Pós-Graduação em Ciência da Informação da Universidade Federal de Santa Catarina, Brasil. E-mail: igao.sa@gmail.com.

** Doutora em Educação pela Pontifícia Universidade Católica de São Paulo, Brasil. Professora do Curso de Ciências da Informação e Documentação da Universidade de São Paulo, Brasil.

E-mail: smostafa@terra.com.br.
}

\section{INTRODUÇÃO}

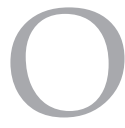

pensamento começa com um problema. É o problema que força o pensamento pensar. Nosso problema é perguntar se é viável o pensamento de Deleuze e Guattari para compreender os fenômenos da área de informação. Deleuze é um filósofo contemporâneo importante, contudo seu pensamento ainda traz muita pontencia desconhecida. É o que sugere Foucault (1995), quando afirma que o século XXI poderia ser deleuziano, por Deleuze. Foucault diz isso no mesmo parágrafo em que enaltece a grandeza de Diferença e Repetição e a Lógica do Sentido, obras que seguiriam por muito tempo nos horizontes de nossas mentes (FOUCAULT, 1995).

A Área de Informação adquiriu força nos últimos séculos, e aponta como importante elemento na constituição da sociedade por permear a esfera das tecnologias de informação e seus efeitos sociais. Por isso, neste século XXI, a área adensa-se como conjunto de conhecimentos fundameentais para o desenvolvimento economico, social e cultural.

Deleuze é um filósofo que não cede à virada linguística. Também não adentra as vertentes cognitivas. Assim, não apresenta grande interesse pela teoria da informação ou pela comunicação media por signos. Busca em sua filosofia uma afastamento da comunicação, do markenting, e outras áreas que de alguma forma compartilha interesse com a Área de Informação. Afirma que a filosofia não é comunicação (DELEUZE; GUATTARI, 2010), pois não apresenta compromisso com o consenso, e sim com o conceito e, o conceito filosófico não é construído para ser comunicado, mas para ser pensado. Isso porque, para Deleuze, a filosofia 
é um movimento radicalmente contrário ao autoritarismos, e a linguguem e a comunicação são por natureza fascistas ${ }^{1}$. Na medida em que falamos, somos obrigados a tomar certos lugares, a fazer determinadas escolhas. Nesse sentido, fascimo e linguagem caminham juntas. Há também o macro fascismo, que exerce poder por meio da burocracia do estado ou pelas condições do mercado, mas tratamos aqui especificamente dos microfascismo, que opram nessa dimensão informacional. Nesse sentido, há um horizonte distópico quando olhamos ao futuro do processamento de dados e informações no contexto em que máquinas processão, inferem e condicionam as dinâmicas sociais.

Normalmente a Área de Informação projeta outro olhar, a de que a informação, conjunta com a mensagem, pode ampliar a dinâmica de emanciapação social (FREIRE; ARAÚJO, 2012). Também pode ampliar as condições para a inovação tecnológica e industrial. Esse entendimento, mas disseminado na literatura da área nós faz perguntar, a que serve o pensamento de Deleuze e Guattari à esta área?

Para tanto, apontamos como o fascismo e a informação estão relacionados, o que faz do controle da informação uma necessidade para o exercício do poder na sociedade contemporânea. Abordamos o duplo caráter da informação entendida sob o signo do fascimo, onde a informação é operada como vetor da vigilância ou como como palavra de ordem. Apontamos, segundo Deleuze e Guattari, como a informação é sistematizada em seu uso fascista, junto com a ordem, o enunciado, a faculdade da ordem e a obediência, contudo demonstramos que há uma brecha pela qual podemos operar a informação por outras perspectivas.

Para isso, saltamos do estrato da informação, para o do agenciamento, o qual engendra a informação e as disputas sobre seu controle, apontando que a identificação do agenciamento é ponto estratégico para pensar a informação de modo não-fascista. Nessa conjuntura é preciso compreender a Área de Informação como uma ciência criativa, que traça um plano e cria por linhas que fogem

I “A linguagem, lembra ele, não é reacionária nem progressista, ela é simplesmente fascista: ela nos obriga a dizer certas coisas, a ocupar certos lugares, posições - homem-mulher, mestre-aluno, branco-negro, direita-esquerda etc." (PELBART, 2005, p. 1325). do poder. Por isso propomos o informe, como plano científico, sobre o qual podemos ocupar de modos contra-hegemônicos, e construir novas concepções de informação.

\section{A NOÇÃo DE INFORMAÇÃO EM DELEUZE}

Se há um visão de que a informação é um elemento com potencia de emancipar as pessoas em nossa sociedade (FREIRE; ARAÚJO, 2012), uma contraposição é feita por autores que dscorrem sobre os perigos que o controle de nossa informações fornece aos insteresses de emprepresas e governos (BEZERRA; CAPURRO; SCHNEIDER, 2017). A problemática levantada aqui se estabelece quando Deleuze propõe uma noção de informação vinculada à sociedade de controle. Pois, o caminho que eticamente interessa é o da resistência ao controle, e não a da manutenção ou ampliação do poder exercido. A resistência ativa, afirmativa, que também promova ataques aos padrões, agentes e códigos de dominação. Conforme Deleuze (1992, p. 219), "São as sociedades de controle que estão substituindo as sociedades disciplinares", as quais fundam-se em formas ultrarrápidas de controle ao ar livre e, sobre tais sociedades, "Não cabe temer ou esperar, mas buscar novas armas" (idem).

A Área de Informação é comprometida com a gestão de fluxos comunicacionais, por meio de processos de coleta, análise, preservação e disponibilização das informações, a fim de ampliar a eficiência das relações burocráticas, financeiras e culturais. A área é facilmente visualizada como componente importante no panorama da sociedade de controle. Pela perspectiva do filósofo francês, é fácil correlacionar a informação ao fascismo. $\mathrm{Na}$ conversa publicada sob o título Os intelectuais e o poder, Foucault e Deleuze tratam do poder, caracterizado como difuso, e sua relação com o poder, o desejo e o interesse. Lembram que o fascismo não foi simplesmente o exercício de opressão de uma autoridade sobre uma massa passiva, ao contrário, em algum momento o fascismo foi desejado, havia interesse de grupos amplos de que o poder fosse exercido por poucos sobre muitos, levado a suas últimas consequências. 
As tendências nas tecnologias de informação como o Big Data e a Inteligência Artificial, apontam para o fim da democracia como a conhecemos hoje, pois impactam nas formas de vida, em como se dão as relações sociais, como se comercializa, como se comportam os indivíduos, e pode condicionar opções que vão dos hábitos alimentares aos intelectuais. O fascismo é difuso, e toma sua forma local necessária para exercer poder. Mas para isso, é imponderável o controle dos dados e informações que indicam comportamentos e preferências. A informação é necessária em dois sentidos, na descentralização da ordem objetivando a subserviência e na coleta dos dados que alimentam bancos e promovem as inferências por robôs. A Área de Informação apresenta sua face mais cruel, quando é associada às pesquisas de engenharia social com interesses puramente comerciais ou de vigilância política. Nesse sentido, McQuillan (2015) alerta para a constituição de um Estado de exceção baseado em algoritmos: "My suggestion is that the new algorithmic apparatus can be characterised by the production of states of exception. The result is an increase in actions that have the force of the law but lie outside the zone of legal determination". $\mathrm{O}$ autor nos convoca a aprender contra as máquinas para contrapormos as novas formas de dominação.

Assim, a aproximação entre essa Área de Informação ao pensamento de Deleuze e Guattari não se daria em condições ou ambiências normais, senão num movimento de resistência nos próprios fluxos informacionais que caracterizam a contemporaneidade dos arranjos sociais, políticos e econômicos.

\section{INFORMAÇÃO E FASCISMO: palavra de ordem}

A sociedade de controle necessita da Área de Informação, pois baseia-se em sistemas de geometria variável e linguagens numéricas para obter o controle. São por esses meios que a agenda neoliberal e as políticas econômicas de austeridade são postas: o modelo-empresa substitui o modelo-fábrica; salário flexível pautado em "competência" substitui o salário base; cinde-se a relação trabalhador-sindicato e estudante-escola; amplia-se a competição entre as pessoas que buscam uma vaga, uma bolsa, um emprego, um like. Na sociedade de controle, as chaves para o acesso aos meios de vida social se dão por uma cifra, um código civil e/ ou bancário, o qual define acessos e restrições e, assim a massa torna-se uma amostra, dados, índices de mercados, indivíduos dividuais.

De acordo com Deleuze (1992), as sociedades de controle atuam via máquinas de computacionais, e o controle não se revela mais pelo enclausuramento em fábricas, hospitais ou colégios, mas na própria circulação, que ao condicionar trajetos em vias pré-definidas, estabelece as regras e normas dos movimentos possíveis, das permissões. "Com uma estrada não se enclausuram pessoas, mas, ao fazer estradas, multiplicam-se os meios de controle. Não digo que esse seja o único objetivo das estradas, mas as pessoas podem trafegar até o infinito e 'livremente', sem a mínima clausura, e serem perfeitamente controladas. Esse é o nosso futuro" (DELEUZE, 1999, p. 12).

Assim, na sociedade de controle, a informação apresenta-se primeiramente como um vetor da vigilância e do controle constante. Esther Díaz (2010) aponta a distinção entre a vigilância, prática localizada, e o controle, prática globalizada. Para que a vigilância e o controle sejam exercidos, é necessário padrões, normas e protocolos que possibilitem a coleta, a reunião, a análise e a posterior ação. É nesse sentido que tradicionalmente a Área de Informação opera, uniformizando os fluxos informacionais, e impossibilitando devires.

Há também outra noção de informação sob a ótica do poder, que se direciona em sentido contrário, e fecha o circuito do controle. Decorre da ação compreendida no final das operações de informação. Trata-se da informação transmitida, informação enquanto conjunto de palavras de ordem: "Quando nos informam, nos dizem o que julgam que devemos crer. Em outros termos, informar é fazer circular uma palavra de ordem" (DELEUZE, 1999 p. 10). O filósofo de excêntrico chapéu afirma que a informação está relacionada com a estabilização de crenças e comportamentos, na medida em que configura-se como palavra de ordem.

A palavra de ordem está nos campos de registros, nos catálogos, nos sistemas de organização do conhecimento, na interoperabilidade, noções caras à Área de 
Informação e em sua realização ${ }^{2}$. Na sociedade disciplinar, o exercício do poder resultava de uma distribuição centralizada do espaço e do tempo via as instituições de controle, como a família, a igreja, a fábrica; enquanto que na sociedade de controle tal exercício se dá nos meios de circulação, nas redes e vias. Assim, no âmbito da informação, a sociedade disciplinar efetuava-se nos espaços como biblioteca, arquivo, museu, centro de documentação. Agora, adentramos à outra lógica, a da vigilância cristalizada nos fluxos das redes de informação, nos protocolos de comunicação, nas indexações e recuperações de informação. Tratamos de fluxos que transcendem as delimitações institucionais, que redimensionam o espaço-tempo em função do acesso, da permissão. A palavra de ordem confere a permissão ou não.

Segundo Deleuze e Guattari (2011), a palavra de ordem é o enunciado. Ordem é redundância, pois ela se apoia em outras ordens. Assim, há uma faculdade abominável responsável por estabelecer essa dinâmica, estabelecer as autoridades e as condições da ordem. Emitir, receber e transmitir palavras de ordem é a tarefa dessa faculdade. A informação participa do processo, contudo a ordem e o enunciado não se reduzem à informação. A ordem compreendida na fala e na obediência comporta um traço de morte, pois a vida apenas escuta e aguarda, a vida não se submete. Os pensadores franceses compreende a informação vinculada à essa cadeia, composta por, além da informação, pela ordem, pelo enunciado, faculdade da ordem e a obediência. Essa cadeia que, estruturada na informação, organiza o funcinamento fascista da linguagem, que confere à informação o uso fascista.

Contudo, há uma fissura apontada pelos pensadores franceses nesse sistema conceitual de informação, ordem, enunciado e obediência. Em dado momento do livro Mil Platôs, eles

2 Um exemplo característico foi o caso de Tarnac Nine. Um folheto político francês intitulado de $A$ Insurreição que Vem, escrito por um grupo anônimo que assina como Comitê Invisível, foi publicado em 2007, com análises sobre os "colapsos iminentes" da cultura capitalista. Em 2008, policiais investigam se um grupo de jovens foram responsáveis por um ato terrorista, tendo como um dos indícios da investigação a suspeita de que esses jovens eram os autores do folheto. A investigação falhou no sentido de provar a ligação do folheto com o atentado, assim como a do folheto com seus supostos "autores" (OSÓRIO, 2016). O que chamamos a atenção aqui é para como a ausência do metadado "autor" prejudicou o controle por parte do Estado, que buscou resolver o caso de terrorismo pela atribuição de autoria do folheto político. apontam a cisão entre informação e linguagem. “A informação é apenas o mínimo estritamente necessário para emissão, transmissão e observação das ordens consideradas como comandos" (DELEUZE; GUATTARI, 2011, p. 13).

Se a linguagem é composta por palavras de ordem transmitidas por informações, há um espaço em que informação e linguagem se divorciam. Os franceses destacam a comunicação das abelhas nos estudos de Beveniste, pois as abelhas se comunicam mesmo sem uma linguagem. A abelha que viu o alimento pode comunicar à uma segunda que não viu, contudo, a segunda não pode comunicar a uma terceira. Assim os filósofos confirmam que a linguagem não se contenta em sair de um primeiro e chegar a um segundo, mas exige que a cadeia prossiga. “É nesse sentido que a linguagem é a transmissão de palavra funcionando como palavra de ordem, e não comunicação de um signo como informação. A linguagem é um mapa, e não um dequalque" (DELEUZE; GUATTARI, 2011, p. 14). A dissociação pode indicar que a informação apresenta outras facetas além dos imperativos do poder. A cisão entre informação-linguagem potencializa uma separação entre informaçãoordem.

\section{DA INFORMAÇÃO AO AGENCIAMENTO}

A informação se situa entre enunciado e fala, os quais se relacionam imanentemente, contudo sem estabelecer uma identidade, "A relação é antes de redundância" (DELEUZE; GUATTARI, 2011, p.17), definida por uma "obrigação social" que articula enunciado e fala. A redundância é anterior a palavra de ordem e a informação, é a condição da transmissão das palavras de ordem. A redundância revelase sob duas formas, a da frequência, relativa a significância da informação, e a forma da ressonância, concernente a subjetividade da comunicação. A redundância submete a informação e a comunicação, assim como a significação e a subjetivação. Assim, para Deleuze e Guattari (2011) ela separa a informação da comunicação em duas formas, e ratifica a alta hierarquia da significação dominante e a ordem estabelecida de subjetivação. Mas como rebelar a informação da redundância própria 
desse sistema? Será preciso ampliar o olhar aos agenciamentos que compreendem a estrutura no qual o poder se efetua. Esse é nosso principal interesse ao aproximar o pensamento de Deleuze e Guattari à Área de Informação, produzir a revolta contra o controle, esse estabelecido mesmo em âmbito semântico, no signo "informação".

Feita de enunciados, as palavras de ordem são transmitidas por informações e, quando transmitidos os enunciados, há indivíduos nítidos. Sobre palavra de ordem: "prendam Rafael Braga!", os beneficiados pela conservação das condições desiguais de alcances dos serviços sociais emitem a palavra ao poder público, que obedece. Rafael foi vítima do abuso de autoridade, para tornar-se índice aos que se manifestavam em 2013. Contudo, Deleuze e Guattari (2011) contestam a individualidade do processo enunciativo, destacando seu caráter social, pois o processo é fundado em agenciamentos coletivos.

É o agenciamento coletivo que pode requerer ou não a individuação e a subjetivação dos enunciados, já que, a nível dos agenciamentos coletivos, o discurso é indireto e livre:

não há contornos distintos nítidos,
não há, antes de tudo, inserção
de enunciados diferentemente
individuados, nem encaixe de
sujeitos de enunciação diversos, mas
um agenciamento coletivo que irá
determinar como sua consequência os
processos relativos de subjetivação, as
atribuições de individualidade e suas
distribuições moventes no discurso
(DELEUZE; GUATTARI, 2011, p. 18)

O que temos encontrado em parte na Área de Informação é um empenho grande, de longa data, em individualizar e em sujeitar, por meio da informação. $O$ uso das palavras de ordem redundantes que reforçam os ideais da burocracia pública e do mercado, representados pelos ideais de gestão, de eficiência, de autoridade e de uniformidade. As proposições da racionalidade discursiva dominam os anseios científicos da área, pondo em cheque as condições de criação em função da construção de consensos.

Contudo, saltar de uma informação aos agenciamentos coletivos pode ser um caminho alternativo para se trabalhar a informação de uma outra perspectiva. Agenciamento coletivo é definido pelo "complexo redundante do ato e do enunciado que efetua necessariamente" (DELEUZE; GUATTARI, 2011, p. 19), o agenciamento revela as palavras de ordem numa palavra. Atravéns do agenciamentos, podemos revelar as estruturas que aplicam o uso fascista da informação.

Deleuze (1999) traz a noção de contrainformação, como algo que resiste ao poder e a morte. Em toda sua obra, Deleuze e Guattari propõe um pensamento vitalista. A imprevisibilidade do percurso proposto na aproximação da Área de Informação com o pensamento de Deleuze e Guattari - da informação ao agenciamento coletivo - pode ser o vetor de abstração, que desmonta os fundamentos tradicionais da Área de Informação e proclama a novidade.

O trajeto implica no retorno ao plano de imanência ${ }^{3}$, o mergulho no caos. O problema da informação não seria mais o do controle, mas o da rebeldia da informação, e de possibilidades à novos enunciados, de liberdade à Rafael Braga! Trata-se de introjetar um vírus e ativar piratarias na sociedade de controle, estabelecer linhas de fuga dos monitoramentos e vigilâncias. Destacamos essa potencia vital e necessária à Área de Informação, que é tolhida constantemente por categorias epistemológicas, por métodos cientificizados e por reconhecimento restritivo dos estados de coisa. Talvez assim, possamos nos aproximar da noção de informação de maneira mais criativa do que tradicionalmente à Área de Informação tem feito, dado que está é composta com base nas necessidades de controle e eficiência. Mas afinal, o que entende-se por Área de Informação?

\section{COMO SE APRESENTA A ÁREA DE INFORMAÇÃO?}

Como tecer um discurso sobre um movimento teórico e prático que diz respeito ao tratamento documental de modo a contemplar as questões desenvolvidas em diferentes disciplinas se nenhuma dessas dá conta de abranger tal movimento? Não abrange porque

\footnotetext{
3 Conceito filosófico apresentado por Deleuze e Guattari (20I0), como - local abstrato e real, de onde as substâncias ascendem a realidade. O plano é o local original das ideias científicas ou filosóficas, antes de adquirirem uma forma.
} 
esse movimento é maior e anterior à própria constituição dessas disciplinas científicas ou nãocientíficas que se proclamam como detentora desse saber. A Biblioteconomia desde sua origem lidou com a ordenação de livros em classes e com sínteses simbólicas que permitissem a identificação de um conteúdo documental sem a necessidade de acessar integralmente o documento. A Bibliografia contribuiu com o desenvolvimento de formatos de descrição bibliográfica, com a montagem de listas e catálogos. A Documentação projetou o mundo conectado a partir dos documentos portadores de conhecimentos, todos descritos, classificados, indexados e acessíveis universalmente. A Organização do Conhecimento, área que busca uma cientifização contemporânea pautada no conceito e no conhecimento e em processos de representação dos mesmos. A Ciência da informação, com o enfoque na recuperação, nos processos de indexação e na abordagem mais próxima das engenharias para uma recuperação mais eficaz. Ainda, lembramos da Arquivologia e da Museologia, disciplinas que desenvolveram suas técnicas, manuais e reflexões próprias sobre o fenômeno documento.

Como fazer referência ao movimento sem silenciar nenhuma dessas áreas? É um desafio que se coloca a quem pretende estudar o movimento teórico-prático do tratamento documental. Não temos a solução para a pergunta, mas algum caminho precisa ser aberto. Utilizaremos o termo Área de Informação para nos referirmos à esse movimento. Uma clareira no meio das tensões disciplinares, pela qual talvez possamos avistar um pouco de luz.

Não propomos um conceito de "Área de Informação", tampouco uma noção "guardachuva", como foi designada por vezes à Ciência da Informação nas últimas décadas. A generalização do tipo "guarda-chuva" requer uma identificação de fatores comuns que aproxime as disciplinas sob critérios de semelhanças, a partir de suas identidades. $\mathrm{O}$ ponto é que cada uma dessas disciplinas ou ciências tem uma motivação, justificativa e propósito próprio. Cada qual em seu tempo, em seu espaço, sua história. Contudo, mantemos o termo que nos dá condição de referenciar o movimento.

Todo campo é constituído por forças, que se manifestam por meio de diferentes formas. Forças e formas se consolidam ou se desconsolidam na própria dinâmica de uma área qualquer. Com Foucault tornou-se evidente que o saber é um conjunto de visibilidades/ invisibilidades e de enuciabilidade/ inunciabilidade que atuam num determinado tempo-espaço exercendo poder (DELEUZE, 1988). Quando se opta por uma das disciplinas em detrimento das outras, é uma seleção, que necessita ser justificada. A opção pelo termo "Área de Informação" não deixa de ser uma seleção política, contudo isso se dá mediante a justificativa de que é necessário transitar por entre as disciplinas que suponhamos compor essa área.

Propomos a nomenclatura com pretensões específicas e, além disso, a esse nome já é uma noção adotada no âmbito da Capes (2016), que recentemente modificou o nome da área de Ciências Sociais Aplicadas I para Área de Comunicação e Informação ${ }^{4}$. Daí nossa inspiração. Contudo, não cessa nisso. Adotar a perspectiva "Área de Informação" implica na composição de uma outra dinâmica de criação. Não buscamos assim reafirmar as identidades dos sujeitos ou objetos do conhecimento de cada uma das áreas. Pois, conforme demonstram Deleuze e Guattari (2010), seja na arte, na filosofia ou na ciência, antes de qualquer sujeito ou objeto há um plano sobre o qual se constrói maquinicamente os elementos que compõem a Área de Informação. Esse é um importante ganho na adoção dos termos. Ao invés das identidades fixas da Bibliografia, Biblioteconomia, Documentação, Arquivologia, Museologia, Ciência da informação e Organização do conhecimento, desabilitamos os pressupostos epistemológicos que definem as identidades.

\footnotetext{
4 "A área de Comunicação e Informação (3I) é constituída pelas seguintes áreas básicas: Comunicação, Ciência da Informação e Museologia, com programas de PósGraduação em Arquivologia, Biblioteconomia, Ciência da Informação, Comunicação, Jornalismo e Museologia. São as mesmas áreas básicas anteriormente reunidas nas Ciências Sociais Aplicadas I. Em 2016, a CAPES aprovou a alteração do nome, reconhecendo que a designação pregressa - uma vez que não havia área de Ciências Sociais Aplicadas 2 - era imprecisa e vinha sendo responsável por enganos frequentes no encaminhamento pela comunidade de APCNs e pedidos de auxílio de modo geral, acarretando atrasos e, eventualmente, prejuízo aos interassados. A atual designação - proposta a partir de consulta aos Coordenadores de Programas e aprovada pela CAPES colabora para uma melhor apreciação da área no que tem de específico, bem como compreende adequadamente a diversidade dos programas que a integram." (CAPES, 2016, p. 2).
} 
Tais definições deixam de ser pressuposições e se tornam construções a posteriori ${ }^{5}$.

\section{I O informe e a informação: um plano para a área de informação}

A noção de informação, em seu sentido clássico, diz respeito à conferência de forma ao que é informe, possibilitando o ato de conhecer (matéria informada) o que era desconhecido (o informe) (CAPURRO; HJORLAND, 2003). Assim, aqui chamamos o virtual deleuzoguattariano de 'informe'. O "in" sugere elementos sem formas, elementos intensivos. É do informe que nasce as informações, as novidades.

Todo movimento de "minoração" na Área de Informação - da unidade de informação (livro) ao assunto, do assunto às combinações sintagmáticas, das informações sobre os documentos ao Big Data - todo esse movimento se traduz na exploração do informe. As disciplinas e ciências compreendidas na Área de Informação constroem seus domínios na medida em que enfrentam o informe e se movem sobre o plano de imanência.

Essa perspectiva revela algo bastante discutido na ciência de um modo geral. É o problema das fronteiras do conhecimento, isto é, existem uma enorme gama de problemas que não cabem nas delimitações disciplinares, pois a dinâmica própria do pensamento e do conhecimento são mais velozes, mais dinâmicas do que podem ser as disciplinas e ciências (MORIN, 2015).

Muitos conceitos tentam explicar essa questão na Área de Informação, tais como a intermulti-trans-disciplinaridade, pós-modernidade, complexidade, recursividade. Mas o comum entre esses conceitos é que não podemos mais ser caracterizados como uma ciência tradicional, tal como fora concebida a física ou a biologia nos séculos XVIII e XIX (POMBO, 2010), tal como alguma vez foi pretendido enquadrar uma Documentação, uma Biblioteconomia, Arquivologia, Museologia e uma Ciência da informação. É preciso evocar os planos que se

5 Deleuze e Guattari (2010) afirmam que o plano de imanência (ou de referência) é anterior a constituição das identidades, pois estas são adquiridas posteriormente, sob conjuntos de conceitos filosóficos ou funções e proposições científicas. A consolidação das ideias, dos métodos e tradições de uma área, não são apriorismo, mas são constituídos, são criados. abrem no horizonte sobre o caos, que viabilizam os movimentos criativos, tal como ensinam Deleuze e Guattari (2010).

Assim, para os fins visados nessa pesquisa, chamamos de Área de Informação a área que tem como problema o documento do ponto de vista de seu tratamento técnico motivado pela apropriação potencial que uma comunidade pode realizar. Essa área lida com aspectos físicos do documento, com aspectos conceituais e de assunto, com aspectos pragmáticos de seu uso e, por fim, como os aspectos intensivos dos documentos. Para tanto, constrói seu diálogo entre a Bibliografia, a Documentação, a Biblioteconomia, a Arquivologia, a Museologia, a Ciência da informação. Ainda, busca aportes e subsídios em outros saberes, como a Filosofia, a História, as Ciências Sociais, as Tecnologias, as Ciências Cognitivas, dentre outras possibilidades.

A Área de Informação diz respeito à experimentação informativa que se estabelece nos liames documentais, nesses espaços de transição. Sobre essa experimentação, ela pode ser retratada sob dois momentos: primeiramente a experimentação se coloca sob as condições do informe, das possibilidades inumeráveis do saber, fazendo que os elementos intensivos do informe passem ao plano do saber. Em seguida, as intensidades podem adquirir formas se elas forem retidas no plano. Quando retidas, tais intensidades são distribuídas nesse mesmo plano. As possibilidades de estabilização das categorias sujeito e objeto são momentâneas e locais quando há esse fluxo entre o informe e a forma. Só há sujeito e objeto quando há informação! Só há informação no movimento de imersão no informe seguida pela emersão no plano, o que viabiliza $o$ resgate de intensidades a serem informadas, isto é, distribuídas pelo plano. É nesse posterior momento que as disciplinas da Área de Informação podem se diferenciar, a depender do agenciamento, das situações pragmáticas.

A Área de Informação não tem epistemologia com sujeito do conhecimento ou objeto do conhecimento pré-existentes. Sujeito e objeto são categorias que podem ser constituídas, mas não pré-existem, nem são eternas ou imutáveis (SPINDLER, 2010). Essa compreensão da Área de Informação considera mais os movimentos realizados pelos pensamentos que as essências estáticas de conceitos imutáveis. Entendemos assim a Área de Informação mais 
como movimento do que como uma ciência delimitada por rígidas identidades e paradigmas. As intensidades trazidas do informe à Área de Informação são dinâmicas, instáveis, rebeldes quando estão no virtual, porém, quando distribuídas no plano, vão estabelecendo conexões e adquirindo mais estabilidade, vão adquirindo valor e tornando-se simbólicas, constituído assim, conceitos, ideias, métodos, práticas, hábitos. Aos pensadores da Área de Informação cabem explorar o informe, transitar num veloz ir-e-vir entre o informe e a forma, movimento de criação pela informação, pelo qual se mobiliza um maquinário próprio à área, e se cartografa percursos nômades ${ }^{6}$.

\section{COMO MOBILIZAR UMA MÁQUINA DE GUERRA NA ÁREA DE INFORMAÇÃO?}

Para pensar a informação como novidade, como não fascista, precisamos ocupar o informe. Deleuze e Guattari (2012) afirmam que um meio para explorar o plano é mobilizar uma máquina de guerra. Máquina de guerra é um conceito cuja função é ziguezaguear entre a posição do que é aberto e livre, ao que é fechado e estanque. A nós, é o que está entre o informe (virtal) e a informação (atual). É uma exterioridade, que não está na informação, mas que se relaciona com ela. É aquilo que não pode jamais se comunicar, e tensiona os processos de informação na medida em que se coloca entre o que possível e o impossível de ser informado.

Trata-se de uma força de devir que não se reduz à informação ou ao traço de morte da palavra de ordem. Assim como o controle busca eliminar a máquina de guerra (DELEUZE; GUATTARI, 2012), as práticas de implementação de consensos, de individuação e de normalização buscam o fim da mesma. É o embate entre a máquina de guerra e a informação, entre o comite invisível e a polícia (conforme nota de rodapé 2). A máquina de guerra é um elmento fronteiriço, pelo qual se disputa a informação, pelo qual

6 Tal dinâmica científica pode ser encontrada em Deleuze e Guattari (20I0), quando afirma que para criar, a Ciência explora o Caos, o virtual, por meio de um plano referencial, funções e proposições. Sobre o plano se constituem as entidades formadas, na realidade, enquanto que o plano e o Caos são substâncias reais, mas informes. se estabelece seu uso pelo poder, ou explora a brecha, a contra-informação, o infomre.

A relação entre a informação e a máquina de guerra não é evolutiva ou encadeada, mas paradoxal, porque ao mesmo tempo, a máquina de guerra é utilizada em função do informe, pondo em variação as intensidades do plano que não mais serão informadas.

$\mathrm{O}$ informe e a informação disputam espaços topológicos, aquele buscando ampliar as possibilidades de sentido, e esse em controlar semanticamente vocabulário e a informatividade documental. É por meio da máquina de guerra que se salta da informação ao agenciamento, que se desindividualiza em num movimento de rebeldia.

Deleuze e Guattari (2012) explicam que a máquina de guerra opera entre dois pólos, o da ciência de Estado (maior) e a ciência nômade (menor). A máquina de guerra propicia a ciência de Estado a apropriação de novidades que são desestabilizadoras apenas num primeiro momento, pois assim que incorporada, condiciona-se as proposições epistemológicas, ontológicas e metodológicas desse espaço. Também é mobilizada pelos movimentos nômades, que destroem certezas entoadas pela ciência régia. É a máquina de guerra que garante a dinamicidade inerente à ciência, articulando seu polo mais veloz e intensivo ao polo mais referencializado e extensivo. A ciência do Estado, também chamada de ciência régia, é pautada na técnica, no método, na medição. Já a ciência menor é excêntrica e "parece muito difícil de classificar, e cuja história é até difícil de seguir". A ciência nômade volta-se à exploração do espaço aberto ou liso, um espaço que é topológico e vetorial, desconhecido. Assim, procura abrir-se ao devir ao invés da estagnação, do eterno ou do idêntico. Reconhece o espaço liso conforme a distribuição de fluxos se dá. Contradiz isso a ciência de Estado com seu espaço métrico, estriado, o qual diz antes por sua medida e por uma distribuição planejada. Essa é a lógica que organiza a Área da Informação quando está busca o controle da informação, estabelecer fascismos informacionais.

A ciência nômade não é teoremática, mas problemática. Isto significa que, diferentemente da ciência régia, que vai do gênero às espécies por meio das diferenças específicas ou também por dedução da essência estável às propriedades, 
a ciência menor orienta-se de um problema aos acidentes que são possibilidades de solução, e que não estão livres de "deformações, transformações, passagens ao limite, operações onde cada figura designa um acontecimento muito mais que uma essência" (DELEUZE; GUATTARI, 2012, p. 26), tal como é o processo quando a Área de Informa procura explorar o informe. Contudo os dois tipos de ciência são separados apenas por um limiar permanentemente móvel que condiciona a relação entre ambas. Entre as forças de soberania e da mobilização da máquina de guerra, ocorre a membrana que sustenta a tensão entre as duas, uma fronteira maleável, espaço sobre o qual é necessário estar atento, pois nos movimentos de fronteias que a criação técnica e científica acontece. Isso significa que a criação não está na informação própria, mas no limiar que a separa do informe. Não se trata de mediar a informação, mas de experiência, ou de se articular numa experiência possível.

A soberania da ciência de Estado depende das polaridades, das binaridades, que definem e mantém as estruturas de saber-poder, do visível e do enunciável. Assim que a Área de Informação tradicionalmente se relaciona com outros campos, produz taxonomias, classificações, indexadores, pois são as invariáveis, os consensos e pressuposições que mantém tais estruturas. A ciência nômade batalha para colocar as invariáveis em variação contínua e, por isso, sozinha, não constrói formas gerais, preocupa-se apenas com a captura das singularidades. Esse seria o meio para trabalhar no/com o informe. Assim, ficar em apenas um dos polos não resolve a questão, não explica a Área de Informação. Mas o movimento dialético entre informe e informação, entre o plano aberto e o estrato fechado, somente assim se constitui a Área de Informação.

Se a informação lida com as representações, que são reproduções elevadas, quando lidamos diretamente com o informe a partir dos documentos, prosseguimos por perseguição: "seguir não é o mesmo que reproduzir, e nunca se segue a fim de reproduzir. $\mathrm{O}$ ideal da reprodução, dedução ou indução faz parte da ciência régia em todas as épocas, em todos os lugares" (DELEUZE; GUATTARI, 2012, p. 41). Para o procedimento de reprodução, tempo e lugar são meras variáveis as quais se contatam as constantes: "Reproduzir implica a permanência de um ponto de vista fixo, exterior ao reproduzido" (idem). Seguir é estar a procura das singularidades de uma matéria, um material, é engajar-se nas variações continuas, sem pretender extrair constantes, é buscar os nãoditos, o que ainda é invisível, o que ainda não é saber.

\section{COMO ENTÃO TRAÇAR UM CAMINHO NÔMADE E SEGUIR O INFORME?}

A obra de Deleuze e Guattari parece apontar diversos caminhos. Abaixo listamos alguns dos principais conceitos que podem ressoar ou que já demarcam alguma presença na Área de Informação, e que auxiliam na exploração nômade de um plano de imanência.

- Menor: implica no movimento de minoração, de busca por perspectivas menores, fora de eixos ou categorias demarcadas pelo olhar predefino pela tradição filosofia e científica ocidental. $\mathrm{Na}$ Área de Informação, destacamos o conceito de Linguagens Documentária Menor, produzido por Mostafa como proposição a partir da noção de literatura menor (MOSTAFA; NOVA CRUZ, 2011).

- Semiótica assignificante: a semiótica preocupada na formalização dos regimes de signos a partir da materialidade informada. A perspectiva não é delimitar a interpretação, pelo contrário, é abrir possibilidade interpretativas. Assim, e possível explorar documentos como livros, fotografias, filmes para processo informacionais mais abertos à multiplicidade (SILVA et al., 2013).

Processos de Atualização/ Virtualização: os processos revelam a dinamicidade com que o mundo se transforma, e a busca para compreender esses fluxos pode revelar como são condicionados outas tantos fluxos pelos quais estamos acostumados e conviver (MOSTAFA, 2013).

- Rizoma: conceito que questiona a estrutura de árvore e as divisões binárias. A lógica rizomática aproxima as concepções da área à perspectivas mais dinâmicas e, a compreensão do funcionamento do rizoma 
pode subsidiar críticas e produções da área (MOSTAFA; AMORIM; SOUZA, 2014).

- A dimensão acontecimental: o documento e/ou a informação apresentam um caráter incorporal, acontecimental, que necessita ser explorado. É por meio dele que entenderemos mais o afeto que as informações nos causam (AMORIM; MOSTAFA, 2017; AMORIM; BRASCHER, 2017).

- $\quad$ O afeto: outra dimensão pouco explorada pelas lentes cientificizantes. O afeto é imprescindível para a informação, pois é um dos meios para a informação não passar desapercebida (NOVA CRUZ; MOSTAFA, 2014).

- $\quad$ Agenciamentos e Máquinas: revelam as estruturas que articulam determinada realidade, no caso, realidade informacional ou documental (AMORIM; CAFÉ, 2017)

- Planos e conceitos: A Área de Informação confere grande valor aos estudos sobre epistemologia. Ao invés de sujeito e objeto do conhecimento, o discurso pode ficar mais interessantes se pensarmos a informação longe dessas categoriais, como pelos conceitos de plano e conceito (MOSTAFA, 2013).

- Deslizamento de planos: Deleuze e Guattari (2010) nos ensinam como os planos deslizam um sobre o outro, frutificando a criação. Os planos de arte, filosofia e ciência se tocam e é mais uma via de explorar o pensamento dos filósofos na Área de Informação (MOSTAFA; AMORIM; SABBAG, 2018).

\section{8 ÀS MICROREVOLUÇÕES: algumas considerações}

Foucault (1977) perguntou em Introdução à vida não-fascista: “Como fazer para não se tornar fascista mesmo quando (sobretudo quando) se acredita ser um militante revolucionário? Como liberar nosso discurso e nossos atos, nossos corações e nossos prazeres do fascismo? Como expulsar o fascismo que está incrustado em nosso comportamento?". Especificamos: como compor com a Área de Informação sem tornar-se fascista? Como ter práticas informacionais não-fascistas? Como pensar uma área afastando-se do fascismo?
Assim, sete "princípios essenciais" foram propostos por Foucault (1977, p. 2) para escapar do fascismo.

1. Libere a ação política de toda forma de paranóia unitária e totalizante;

2. Faça crescer a ação, o pensamento e os desejos por proliferação, justaposição e disjunção, mais do que por subdivisão e hierarquização piramidal;

3. Libere-se das velhas categorias do Negativo (a lei, o limite, a castração, a falta, a lacuna), que o pensamento ocidental, por um longo tempo, sacralizou como forma do poder e modo de acesso à realidade. Prefira o que é positivo e múltiplo; a diferença à uniformidade; o fluxo às unidades; os agenciamentos móveis aos sistemas. Considere que o que é produtivo, não é sedentário, mas nômade;

4. Não imagine que seja preciso ser triste para ser militante, mesmo que a coisa que se combata seja abominável. É a ligação do desejo com a realidade (e não sua fuga, nas formas da representação) que possui uma força revolucionária;

5. Não utilize o pensamento para dar a uma prática política um valor de verdade; nem a ação política, para desacreditar um pensamento, como se ele fosse apenas pura especulação. Utilize a prática política como um intensificador do pensamento, e a análise como um multiplicador das formas e dos domínios de intervenção da ação política;

6. Não exija da ação política que ela restabeleça os "direitos" do indivíduo, tal como a filosofia os definiu. $\mathrm{O}$ indivíduo é o produto do poder. O que é preciso é "desindividualizar" pela multiplicação, o deslocamento e os diversos agenciamentos. O grupo não deve ser o laço orgânico que une os indivíduos hierarquizados, mas um constante gerador de "desindividualização";

\section{Não caia de amores pelo poder.}

Tais princípios são meios para as microrevoluções, que devem ser praticadas. Ao domínio da informação, podemos adaptar outros princípios, tais como:

1. Liberte-se das pretensões universalistas e concepções que definem suas posições políticas como neutras; 
2. Conecte, coopere, colabore, crie relações horizontais ao invés de hierarquias;

3. Libere-se das velhas categorias do Negativo (a lei, o limite, a castração, a falta, a lacuna), que o pensamento ocidental, por um longo tempo, sacralizou como forma do poder e modo de acesso à realidade. Prefira o que é positivo e múltiplo; a diferença à uniformidade; o fluxo às unidades; os agenciamentos móveis aos sistemas. Considere que o que é produtivo, não é sedentário, mas nômade (mantido);

4. Busque linhas de fuga que o alegre nos embates contra o autoritarismo;

5. Aja informacionalmente de modo a intensificar o pensamento teórico e crítico e utilize da análise para amplificar politicamente as práticas de informação. Considere o político em suas ações intelectuais e práticas.
6. Faça da prática informacional um meio para a desindividualização, para o rompimento do poder, inclusive em relação as categorias de sujeito e comunidade. O comum se dá no plano intensivo, o qual a prática informacional pode alcançar.

7. Não caia de amores pelo poder (mantido).

O início desse século traz pelas tecnologias de informação o ovo da serpente ${ }^{7}$. Para que esse ovo não rache, é preciso que profissionais envolvidos com a informação se empenhem na transformação dessa realidade. Abrir a informação ao devir, rasgar o firmamento e permitir que um feixe de ilumine e crie, na medida em que se distribua sobre o plano de imanência da Área de Informação. É preciso que atualizemos o próprio entendimento sobre a área, para reorientarmos os direcionamentos políticos da Área de Informação.

7 Referencia ao filme de Bergman que aborda o contexto em que se solidificou o nazismo.

Artigo recebido em 2I/03/20I8 e aceito para publicação em 05/05/20I8

\section{THE IMPACT PLAN OF THE INFORMATION AREA AND THE WAR MACHINE}

ABSTRACT It deals with the notion of control society in the conception of Deleuze and Guattari in order to develop a critical approach on the notion of information for the Information Area. The notion of information is linked to the control society. The Information Area is committed to the management of communicational flows. The information is revealed as empowering the control society in that it allows the control of the data. To control, the information is necessary in two senses: in the decentralization of the order objectifying the subservience and in the extraction of the data that feed computational banks. Thus, the approximation between this area to the thought of Deleuze and Guattari occurs in a movement of resistance in the own information flows. Information is constituted between utterance and speech, and conditions the transmission of the word of order. But the transmission is shrouded in agency that precedes the individualities. Thus, mobilizing a war machine to jump from an information to the collective agency can be an alternative route to the Information Area.

Keywords: $\quad$ Area of Information. Control Society. War machine. Information. Inform.

\section{REFERÊNCIAS}

AMORIM, I.; BRASCHER, M. M. Fissuras indômitas da representação. In: Encontro Nacional de Pesquisa em Ciência da Informação, 18., 2017, Marília. Anais... Marília: Unesp, 2017.
AMORIM, I. S.; CAFÉ, L. M. Agenciamento e Análise de Domínio: um encontro possível. Informação \& Sociedade, v. 27, n. 2, 2017.

AMORIM, I. S.; MOSTAFA, S. P. Informaçãohappening e o romance da Ciência da Informação. Revista ACB, v. 22, n. 3, p. 467-482, 2017. 
BEZERRA, A. C.; CAPURRO, R.; SCHNEIDER, M. Regimes de verdade e poder: dos tempos modernos à era digital. Liinc em Revista, v. 13, n. 2, 2017.

CAPES - Coordenação de Aperfeiçoamento de Pessoal de Nível Superior. Relatório de avaliação 2013-2016. Quadrienal 2017. 2016. Disponível em: < http://capes.gov.br/images/documentos/ Relatorios_quadrienal_2017/RELATORIO_ QUADRIENAL_COMUNICACAO.pdf $>$. Acesso em: 29 jan. 2018.

CAPURRO, R.; HJØRLAND, B. The concept of information. Annual review of information science and technology, v. 37, n. 1, p. 343-411, 2003.

DELEUZE, G. Foucault. São Paulo: Brasiliense, 1988.

O ato de criação. Folha de São Paulo, v. 27, p. 4, 1999. Disponível em:< http:// www.filoczar.com.br/filosoficos/Deleuze/ Gilles \%20Deleuze\% 20-\%20O\%20ato \%20de\% 20 Cria\%C3\%A7\%C3\%A3o.pdf >. Acessado em: 22 jan. 2018.

Post-scriptum sobre as sociedades de controle. In: Conversações (1972-1990). Rio de Janeiro: Ed. 34, p. 219-226, 1992.

DELEUZE, G.; GUATTARI, F. Mil platôs: capitalismo e esquizofrenia 2. Rio de Janeiro: Editora 34, 2011. vol. 2.

Mil platôs: capitalismo e esquizofrenia 2. Rio de Janeiro: Editora 34, 2012. vol. 5.

O que é Filosofia?. Rio de Janeiro: Editora 34, 2010.

ESTHER DÍAZ. Las grietas del control: vida, vigilancia y caos. Biblos, 2010.

FOUCAULT, M. Introdução à vida não fascista. In: Deleuze, G. e Guattari, F. Anti-Édipo: Capitalismo e Esquizofrenia. 1977.

FOUCAULT, M.; DELEUZE, G. Os intelectuais e o poder. Microfísica do poder, v. 17, p. 69-78, 1979.

FREIRE, I. M.; ARAUJO, V. M. R. H. de. A responsabilidade social da ciência da informação. Transinformação, v. 11, n. 1, 2012.
MCQUILLAN, D. Algorithmic states of exception. European Journal of Cultural Studies, v. 18, n. 4-5, p. 564-576, 2015.

MORIN, E. Introdução ao pensamento complexo. 5.ed. Porto Alegre: Sulina, 2015.

MOSTAFA, S. P. Filosofia da diferença e a ciência da informação. Rio de Janeiro: E-papers, 2013.

MOSTAFA, S. P.; AMORIM, I. S.; SOUZA, L. M. A.Filosofia e discurso na ciência da informação: tessitura de encontros. Logeion: Filosofia da Informação, Rio de Janeiro, v. 1, n. 1, p. 6-19, 2014.

MOSTAFA, S. P.; NOVA CRUZ, D. V. Por uma linguagem documentária menor. In: BOCCATO, V. R. C.; GRACIOSO, L. S. (Org.). Estudos de linguagem em ciência da informação. Campinas: Alinea, 2011. p. 69-96.

MOSTAFA, S. P.; AMORIM, I. S.; SABBAG, D. M. A. Eros e a Ciência da Informação. Em Questão, 2018.

NOVA CRUZ, D. V.; MOSTAFA, S. P. Informação-afeto: real sem ser atual, ideal sem ser abstrata. PerCursos, v. 15, n. 29, p. 39-56, 2014.

OSÓRIO, W. Guerrilha performática: arte -política e terrorismo estatal. In: CERBINO, Beatriz; OLIVEIRA, Luiz Sérgio de; TABORDA, Tato [Orgs.]. Subversões de protocolos: uso impróprio. PPGCA-UFF: Niterói, 2016,p. 19-34.

PELBART, P. P. Solidão, fascismo e literalidade. Educação \& Sociedade, Campinas, v. 26, n. 93, 2005.

POMBO, O. Dispersão e unidade: Para uma poética da simpatia. In: LARA, M. L. G.; SMITH, J. W. (Org.). Temas de pesquisa em Ciência da Informação no Brasil. São Paulo: Escola de Comunicações e Artes/USP, 2010.

SILVA, A. R. da et al. Deleuze e a semiótica Crítica. Semeiosis: semiótica e transdisciplinaridade em revista, 2013.

SPINDLER, F. Gilles Deleuze: a Philosophy of Immanence. In: BORNEMARK, Jonna et al. Phenomenology and religion: new frontiers. Södertörn University, 2010, p. 149-163. 